\title{
High-Fat Feeding Improves Anxiety-Type Behavior Induced by Ovariectomy in Rats
}

\author{
Ana P. S. Dornellas, Valter T. Boldarine, Amanda P. Pedroso, Lorenza O. T. Carvalho, \\ Iracema S. de Andrade, Tânia M. Vulcani-Freitas, Carla C. C. dos Santos, \\ Cláudia M. da Penha Oller do Nascimento, Lila M. Oyama and Eliane B. Ribeiro*
}

Physiology Department, Escola Paulista de Medicina, Universidade Federal de São Paulo, São Paulo, Brazil

\section{OPEN ACCESS}

Edited by:

Timo Dirk Müller

Helmholtz Zentrum München, Helmholtz-Gemeinschaft Deutscher Forschungszentren $(\mathrm{HZ})$, Germany

Reviewed by:

Matt Carter

Williams College, United States Brian Yee Hong Lam,

University of Cambridge, United Kingdom

Michael murray Scott, University of Virginia, United States

*Correspondence: Eliane B. Ribeiro eliane.beraldi@gmail.com

Specialty section:

This article was submitted to Neuroenergetics, Nutrition and Brain

Health,

a section of the journal Frontiers in Neuroscience

Received: 27 February 2018

Accepted: 24 July 2018

Published: 03 September 2018

Citation:

Dornellas APS, Boldarine VT, Pedroso AP, Carvalho LOT, de Andrade IS, Vulcani-Freitas TM, dos Santos CCC, do Nascimento CMdPO, Oyama LM and Ribeiro EB (2018) High-Fat Feeding Improves Anxiety-Type

Behavior Induced by Ovariectomy in Rats. Front. Neurosci. 12:557. doi: 10.3389/fnins.2018.00557
Menopause-induced changes may include increased incidence of both depression/ anxiety and obesity. We hypothesized that behavioral changes that may develop after ovarian failure could be related to neurochemical and metabolic aspects affected by this condition and that high-fat intake may influence these associations. The present study investigated in rats the effects of ovariectomy, either alone or combined with high-fat diets enriched with either lard or fish-oil, on metabolic, behavioral and monoaminergic statuses, and on gene expression of neuropeptides and receptors involved in energy balance and mood regulation. Female rats had their ovaries removed and received either standard chow $(\mathrm{OvxC})$ or high-fat diets enriched with either lard (OvxL) or fishoil (OvxF) for 8 weeks. The Sham group received only chow diet. Ovariectomy increased feed efficiency and body weight gain and impaired glucose homeostasis and serotonininduced hypophagia, effects either maintained or even accentuated by the lard diet but counteracted by the fish diet. The OvxL group developed obesity and hyperleptinemia. Regarding components of hypothalamic serotonergic system, both ovariectomy alone or combined with the fish diet increased $5-\mathrm{HT}_{2} \mathrm{C}$ expression while the lard diet reduced 5$\mathrm{HT}_{1 \mathrm{~B}} \mathrm{mRNA}$. Ovariectomy increased the anxiety index, as derived from the elevated plus maze test, while both high-fat groups showed normalization of this index. In the forced swimming test, ovariectomy allied to high-lard diet, but not to fish-oil diet, reduced the latency to immobility, indicating vulnerability to a depressive-like state. Linear regression analysis showed hippocampal AgRP to be negatively associated with the anxiety index and hypothalamic AgRP to be positively associated with the latency to immobility. These AgRp gene expression associations are indicative of a beneficial involvement of this neuropeptide on both depression and anxiety measures. The present findings demonstrate metabolic, neurochemical and behavioral alterations after ovaries removal and highlight a positive effect of high-fat feeding on the anxiety-like behavior shown by ovariectomized animals. Since the polyunsaturated ômega-3 intake (fish diet), unlike the saturated fat intake (lard diet), failed to induce deleterious metabolic or neurochemical consequences, further studies are needed focusing on the potential of this dietary component as an adjuvant anxiolytic agent after menopause.

Keywords: hypothalamus, hippocampus, serotonin, lard, fish-oil, neuropeptides 


\section{INTRODUCTION}

Although a connection between metabolic disturbances and psychiatric disorders has been suggested, the mechanisms involved have not been elucidated. Patients with depression have been shown to present inadequate patterns of food intake and glycemic control while diabetic individuals had higher incidence of cognitive impairment, depression and anxiety disorders (Panza et al., 2012; Correia and Ravasco, 2014; Singh, 2014; Barandas et al., 2015).

The proportion of overweight and obese adults has increased worldwide regardless of gender (Ng et al., 2014; de la Iglesia et al., 2016), while the prevalence of anxiety disorders and depression are higher in women than in men (Bromberger and Kravitz, 2011; Kessler et al., 2015). Gender differences related to depression seem to emerge after puberty (Hankin et al., 2007) and to decline years after menopause (Bebbington et al., 2003). Moreover, there is an increased prevalence of mood disorders in post-menopausal women, a condition reportedly aggravated by the presence of diabetes (Anderson et al., 2001; Martins et al., 2002; Kim et al., 2015). Additionally, the association between obesity and depression is highly expressed after menopause but the mechanisms involved are unknown (Perquier et al., 2014; Xiong et al., 2017).

Energy balance is regulated by a complex system in which the hypothalamus plays a pivotal role, integrating signals from both peripheral and central sites to modulate the release of neuropeptides controlling food intake and energy expenditure (Gerozissis, 2008; Yeo and Heisler, 2012). In contrast, the hippocampus is an area highly involved in the control of mood and cognition (Mahar et al., 2014; Anacker and Hen, 2017). Interestingly, it is targeted by peripherally-derived endocrine signs and it has been suggested to participate in the nonhomeostatic control of feeding through regulating the activation of reward memory by food-related cues (Davidson et al., 2005). However, the actions of these hormonal signs on this brain area remain little explored (Kanoski and Grill, 2017).

Estrogen deficiency has been associated with increased body adiposity, impairment of plasma lipid profile, type 2 diabetes and metabolic syndrome (Milewicz et al., 1996; Carr, 2003; Messina et al., 2013). Estradiol has been shown to inhibit feeding via hypothalamic actions. The reported effects of estradiol are complex and include attenuation of ghrelin's orexigenic action (Ferrer-Lorente et al., 2009), inhibition of neuropeptide Y (NPY)/agouti-related peptide (AgRP) orexigenic neurons (Olofsson et al., 2009), potentiation of cholecystokinininduced satiety (Asarian and Geary, 2007), and stimulation of pro-opiomelanocortin (POMC) anorexigenic neurons ( $\mathrm{Zhu}$ et al., 2015). Estradiol-induced hypophagia may also involve hypothalamic serotonergic activation (Pelletier et al., 2007; Silva et al., 2010; Rivera et al., 2012; Santollo et al., 2012). Moreover, estrogens influence brain areas regulating mood and cognition, such as the hippocampus, increasing the availability of monoamines through reduction of monoamine oxidase expression, stimulation of tryptophan hydroxylase, and regulation of serotonin (5-HT) neuronal transport (RenPatterson et al., 2006; Kiss et al., 2012). These data indicate that estrogen deficiency after menopause could facilitate the establishment of both mood disorders and metabolic derangements (Alexander et al., 2007).

The role played by AgRP, NPY, POMC, and CART acting at the hippocampus is not yet understood. Hippocampal infusion of NPY reversed the anxiogenic action of corticotropin releasing factor (Kask et al., 2002; Heilig, 2004) and chronic restraint stress elevated CART gene expression in the hippocampus (Hunter et al., 2007). POMC deficiency decreased hippocampal cell proliferation in rats (Ostwald et al., 2006) while AgRP expression has been associated with hippocampal maturation in human fetal cells (Bai et al., 2005).

Dietary factors may have an impact on both metabolic and mood disorders. We have previously shown, in rats, that fish-oil intake increased neuronal activation of hypothalamic sites expressing anorexigenic mediators (Watanabe et al., 2009). Moreover, n-3 PUFAs presented a protective effect in patients with major depression, acting via serotonergic modulation (Peet and Stokes, 2005; Ross et al., 2007). In mice, the consumption of n-3 diet had an antidepressant-like effect, and increased hippocampal volume, BDNF expression and neurogenesis (Venna et al., 2009). In contrast, despite the obesogenic effect of saturated fatty acids, lard consumption reportedly reduced signs of stress and anxiety in humans and animals (Finger et al., 2011; Singh, 2014), but little is known about its properties in an estrogen deficiency-state.

Based on the above considerations, the present study investigated the effects of ovaries removal, either alone or combined with the chronic consumption of high-fat diets enriched with either lard or fish-oil, on metabolic, behavioral and monoaminergic statuses. Additionally, hypothalamic and hippocampal gene expression of neuropeptides and receptors involved in energy balance and mood regulation have also been analyzed. We hypothesized that behavioral changes that may develop in the absence of ovarian hormones could be related to neurochemical and metabolic aspects affected by this condition and that high-fat intake may impact these associations.

\section{METHODS}

\section{Animals and Diets}

All the procedures were in agreement with the guidelines of the Committee in Research Ethics of the Universidade Federal de São Paulo (CEP 0311/11). Eight-week-old female Wistar rats were weighed and submitted to either bilateral ovariectomy or sham operation, under ketamine/xylazine anesthesia $(66 / 33 \mathrm{mg} / \mathrm{kg}$, ip). After the surgery, they were housed four to five per cage and maintained under controlled lighting ( $12 \mathrm{~h} \mathrm{light/dark} \mathrm{cycle,}$ lights on at 6 a.m.) and temperature conditions $\left(23 \pm 1^{\circ} \mathrm{C}\right)$, with free access to food and water. The ovariectomized rats (Ovx) were assigned to one of three groups (OvxC, OvxL, or OvxF), according to the diet received for the next 8 weeks. The OvxC group received standard rat chow (Control diet, $2.87 \mathrm{kcal} / \mathrm{g}$, $15 \%$ of energy from fat, Nuvilab, Brazil) while the OvxL and OvxF groups received high-fat diets $(3.60 \mathrm{kcal} / \mathrm{g}, 45 \%$ energy from fat) enriched with either lard (Aurora, Cooperativa Central 
Aurora de Alimentos, Brazil) or fish oil (ROPUFA ${ }^{\circledR}$ “ 75 ” $\omega$ 3, Roche, DSM Nutritional Products, Brazil), respectively. The sham-ovariectomized group (Sham) received the control diet.

The high-fat diets were prepared by adding, to the standard chow, $20 \%(\mathrm{w} / \mathrm{w})$ fat, $20 \%(\mathrm{w} / \mathrm{w})$ casein, $10 \%(\mathrm{w} / \mathrm{w})$ sucrose, and $0.02 \%(\mathrm{w} / \mathrm{w})$ butylated hydroxytoluene (Watanabe et al., 2010; Dornellas et al., 2015). The lard diet contained $2 \%$ soybean oil to ensure the adequate content of essential PUFAs (Reeves, 1997).

\section{Food Intake, Body and Fat Pads Weight, and Serum Parameters}

Food intake and body weight were measured weekly. The metabolic efficiency was calculated as [(body weight gain/energy intake)*100]. At the end of the diet treatment, the rats were euthanized after an overnight fast, trunk blood was collected and serum stored at $-80^{\circ} \mathrm{C}$. Uterus and retroperitoneal, gonadal and mesenteric fat pads were dissected and weighed. Ovariectomy was confirmed by uterus atrophy. Glucose, triacylglycerols and cholesterol levels were analyzed by enzymatic methods (Labtest Diagnóstica, Brazil). Serum levels of insulin and leptin were measured by enzyme-linked immunosorbent assays (Millipore Corp., Bedford, USA).

\section{Hypothalamic, Hippocampal and Serum Levels of 5-HT, 5-HIAA, and Catecholamines}

Three days after the infusion experiment and after an overnight fast, some animals were euthanized and their hypothalami and hippocampi were dissected and immediately weighed and homogenized in $1.5 \mathrm{ml}$ of cold $0.1 \mathrm{M}$ perchloric acid containing $0.02 \%$ sodium metabisulfite and $0.7 \mathrm{nM} \mathrm{3,4-}$ dihydroxybenzylamine as internal standard (Watanabe et al., 2010). Levels of serotonin (5-HT) and 5-hydroxyindoleacetic acid (5-HIAA) were analyzed in $200 \mu$ l of serum. After centrifugation, the supernatant was stored at $-80^{\circ} \mathrm{C}$ until analysis. The contents of 5-HT, 5-HIAA, and catecholamines were determined by Highpressure Liquid Chromatography (HPLC) with electrochemical detection.

\section{RNA Extraction and Real-Time Polymerase Chain Reaction (RT-PCR)}

Four days after the behavioral tests, some animals were euthanized and their hypothalami and hippocampi were dissected and immediately stored at $-80^{\circ} \mathrm{C}$ until analysis. Total RNA from hypothalami and hyppocampi were extracted using Trizol protocol (Invitrogen). One nanogram of total RNA, as determined by NanoDrop 1100 (NanoDrop Technologies, Wilmington, DE, USA), was used for cDNA synthesis (High-Capacity cDNA kit, Applied Biosystems). The cDNA was amplified using the TaqMan ${ }^{\circledR}$ Universal PCR Master Mix Kit with specific TaqMan Gene Expression. The following target genes were assessed: serotonin $1 \mathrm{~A}$ $\left(5-\mathrm{HT}_{1 \mathrm{~A}}\right)$ receptor (Rn00561409_s1), serotonin 1B (5$\left.\mathrm{HT}_{1 \mathrm{~B}}\right)$ receptor (Rn01637747_s1), serotonin 2C (5- $\left.\mathrm{HT}_{2 \mathrm{C}}\right)$ receptor (Rn00562748_m1), serotonin trasporter (5-HTT) (Rn00564737_m1), neuropeptide Y (NPY) (Rn01410145_m1), pro-opiomelanocortin (POMC) (Rn00595020_m1), cocaine- and amphetamine-regulated transcript (CART) (Rn01645174_m1), agouti-related peptide (AgRP) (Rn01431703_g1), leptin receptor (ObR) (Rn 01433205_m1), adiponectin receptor 1 (AdipoR1) (Rn01483784_m1), and adiponectin receptor 2 (AdipoR2) (Rn01433173_m1). $\beta$-actin (Rn00667869_m1) was used as endogenous control for normalization. The PCR reactions were performed in a 96-well Optical Reaction Plate (Applied Biosystems, Foster City, CA, USA). The thermocycler parameters were as follows: $50^{\circ} \mathrm{C}$ for $2 \mathrm{~min}, 95^{\circ} \mathrm{C}$ for $10 \mathrm{~min}, 50$ cycles of $95^{\circ} \mathrm{C}$ for $15 \mathrm{~s}$ and $60^{\circ} \mathrm{C}$ for $1 \mathrm{~min}$. Expression of the target genes was normalized against that of the Sham animals. The statistical analysis was performed using the $\Delta \mathrm{Ct}$ value $\left(\mathrm{Ct}_{\text {gene of interest }}\right.$ - $\left.\mathrm{Ct}_{\beta-\text { actin }}\right)$ and the results were expressed using the 2- $\Delta \Delta \mathrm{Ct}$ method (Livak and Schmittgen, 2001).

\section{Behavioral Tests}

\section{Intracerebroventricular Serotonin Injection and Food Intake Measurement}

At the eighth week of treatment, the animals were anesthetized with ketamine/xylazine $(66 / 33 \mathrm{mg} / \mathrm{kg}$, ip) and stereotaxicaly implanted with a guide cannula (21 gauge, $15 \mathrm{~mm}$ length) aimed at the lateral cerebral ventricle (from bregma: $-0.9 \mathrm{~mm}$ posterior, $+1.6 \mathrm{~mm}$ lateral and $-2.5 \mathrm{~mm}$ ventral) (Paxinos et al., 1985). They were then caged individually with free access to food and water during 1 week. After this recovery period, they were fasted for $6 \mathrm{~h}$ and received an intracerebroventricular (ICV) injection of either $5.0 \mu \mathrm{l}$ of vehicle (artificial cerebrospinal fluid, CSF: $145 \mathrm{mmol} / \mathrm{l}$ sodium chloride, $2.7 \mathrm{mmol} / \mathrm{l}$ potassium chloride, $1.2 \mathrm{mmol} / \mathrm{l}$ calcium chloride, $2.0 \mathrm{mmol} / \mathrm{l} \mathrm{di}$-sodium hydrogen phosphate, and $1 \mathrm{mmol} / \mathrm{l}$ magnesium chloride at $\mathrm{pH} 7.4$ ) or $5.0 \mu \mathrm{l}$ of vehicle containing either 200 or $300 \mu \mathrm{g}$ of serotonin (H9523, Sigma-Aldrich, USA). The injections were performed in the animal room immediately before lights off. Following the injection, they were returned to their individual cages and a known amount of diet was offered. Diet consumption was assessed by weighting the food remaining after 12 and $24 \mathrm{~h}$. Each animal was injected twice, receiving vehicle or one serotonin dose, on separate days, two days apart. They were randomly divided so that half the animals received vehicle as the first injection and the other half received serotonin as the first injection. The correct cannula positioning was evaluated by the dipsogenic effect of an ICV $20 \mathrm{ng}$ dose of angiotensin II. All animals failing to drink water were discarded.

\section{Elevated Plus Maze Test}

The maze consisted of two open arms and two closed arms connected by a central platform high off the ground and lit by a dim light. The animals were placed individually on the central platform facing an open arm. The test was performed during $5 \mathrm{~min}$ and was videotaped for subsequent analysis. The time spent, number of entries and distance traveled in the arms were measured by two observers (Pellow et al., 1985). The number of entries and distance traveled in the closed arms were used as a measure of locomotor activity (Campos et al., 2013). The anxiety index was calculated by the equation: 1 -[(open arm time/5 min) + (open arm entry/total entry)]/2. The index values range from 
0 to 1 , with a higher value indicating increased anxiety (Huynh et al., 2011).

\section{Modified Forced Swim Test}

The rats were individually placed in a Plexiglas cylinder (diameter $30 \mathrm{~cm}$, height $50 \mathrm{~cm}$ ) containing water up to $30 \mathrm{~cm}$ (or high enough to prevent the animal from supporting the body with the tail) at $25 \pm 1^{\circ} \mathrm{C}$. On the first day, the animals remained in the cylinder for $15 \mathrm{~min}$ (training session). After $24 \mathrm{~h}$, the procedure was repeated for $5 \mathrm{~min}$ (test session). The test session was videotaped for subsequent analysis. The predominant behavior within each 5-s period was recorded. The following behaviors were assessed: swimming (movements throughout the cylinder), climbing (upward-directed movements with the forepaws along the cylinder walls), immobility (floating with minimal movements with head just above the water) and number of dips (Porsolt et al., 1977). After the sessions, the animals were dried and returned to the home cage.

\section{STATISTICAL ANALYSIS}

Data are expressed as mean \pm SEM. Comparisons among the groups (Sham, OvxC, OvxL, and OvxF) were performed by ANOVA followed by Tukey's test for multiple comparisons. The effect of intracerebroventricular serotonin on food intake was assessed in each group by Student's $t$-tests for dependent measures. The Pearson's correlation coefficient was used to analyze the existence of relationships between behavioral parameters in the elevated plus maze and forced swim tests, and metabolic/gene expression data. Multivariate regression analysis was performed to assess metabolic/gene expression factors influencing behavioral variables. The regression models were constructed based on the statistically significant correlations shown by the univariate analysis. The Statistics Software Package for the Social Sciences (SPSS, v18.0) was used for these analyses.

\section{RESULTS}

\section{Lard Diet But Not Fish Diet Potentiated the Deleterious Effects of Ovariectomy on Body Weight Gain and Metabolic/Hormonal Parameters}

The daily food mass and food energy intakes of the control, lard and fish diets were measured once a week, throughout the 8 weeks, and the cumulative intakes are shown in Table 1. There was no effect of ovarietomy, either alone (OvxC group) or combined with high-fat feeding (OvxL and OvxF groups), on the cumulative food intake, while the cumulative caloric intake of the OvxL group was significantly higher than that of the OvxC group. These findings indicate that, although the two hyperlipidic diets had the same caloric content, only the lard diet induced increments of the caloric intake of the ovariectomized rats.

Ovariectomy, either per se or combined with high-lard intake, increased feed efficiency while the high-fish intake prevented this effect of ovariectomy, indicating a protective effect of the highfish diet. Ovariectomy increased body weight gain and final body weight. In the OvxL group, these parameters were higher than in the OvxC and OvxF groups. These results show that the excess weight gain induced by ovariectomy was deepened by the lard diet but not by the fish diet. Taken together, these data suggest that increased feed efficiency may explain the high body weight gain of the OvxC and OvxL groups but not of the OvxF group.

Body adiposity, estimated by the sum of 3 adipose tissue depots, was higher in the OvxL animals than in all the other groups $\left[F_{(3,44)}=22.817, p=7.55 \times 10^{-9} ; p=1.87 \times 10^{-7}\right.$ vs. Sham; $p=1.43 \times 10^{-4}$ vs. OvxC; $p=1.66 \times 10^{-8}$ vs. OvxF). Additionally, the OvxF group showed decreased adiposity in comparison to $\operatorname{OvxC}(p=0.044)$. These data indicate that ovariectomy associated with lard consumption, but not with fish-oil consumption, caused obesity.

All the Ovx groups showed increased levels of serum glucose, regardless the diet consumed $\left[F_{(3,45)}=11.288, p=1.46 \times\right.$ $\left.10^{-5}\right]$. Insulin levels were higher in OvxL than in $\operatorname{OvxF}\left[F_{(1,20)}\right.$ $\left.=90,527, p=7.25 \times 10^{-8}\right]$. Although without statistical significance $(p=0.597)$, insulin levels of OvxF rats were $62 \%$ lower than those of OvxC animals. These data suggest that fish-oil intake ameliorated the insulin resistance induced by ovariectomy.

Leptinemia was increased in $\operatorname{OvxL}\left[F_{(3,33)}=16.839, p=\right.$ $\left.1.88 \times 10^{-6}\right]$ in relation to all the groups. The OvxF rats showed a nonsignificant $(p=0.511$ ) reduction of leptin levels in relation to OvxC group. These results are in accordance with the adiposity data.

OvxF animals presented reduced triglyceride levels $\left[F_{(3,32)}=\right.$ 9.023, $\left.p=2.23 \times 10^{-4}\right]$ in relation to all the other groups. In addition, total cholesterol levels were higher in $\operatorname{OvxL}\left[F_{(3,20)}=\right.$ $5.817, p=0.006]$ than in Sham $(p=0.024)$, and lower in OvxF than in OvxL $(p=0.014)$. The data indicate that ovariectomy affected blood glucose levels regardless the diet. However, in ovariectomized rats, the consumption of lard impaired while fish-oil intake presented a protective effect on metabolic and hormonal parameters.

\section{Fish Diet Stimulated Hippocampal Serotonergic Activity in Ovariectomized Rats}

Because monoamines participate in the control of both metabolic and behavioral aspects, their serum levels as well as their hypothalamic and hippocampal tissue levels were evaluated and are presented in Table 2 .

Both circulating and hypothalamic levels of serotonin, catecholamines and their metabolites failed to present significant differences among the groups.

In the hippocampus, L-Dopa levels were higher $\left[F_{(3,20)}=\right.$ 4.596, $p=0.016]$ in OvxF than in Sham $(p=0.036)$ and OvxC $(p=0.016)$ rats. 5-HIAA levels were higher in OvxF than in Sham $(p=0.044)$ while serotonin turnover was higher in $\mathrm{OvxF}$ $\left[F_{(3,19)}=3.535, p=0.039\right]$ than in $\operatorname{OvxC}(p=0.038)$. The present data indicate that the serotonergic activity was stimulated in the hippocampus of the OvxF animals. 
TABLE 1 | Body and serum parameters of Sham, OvxC, OvxL, and OvxF groups.

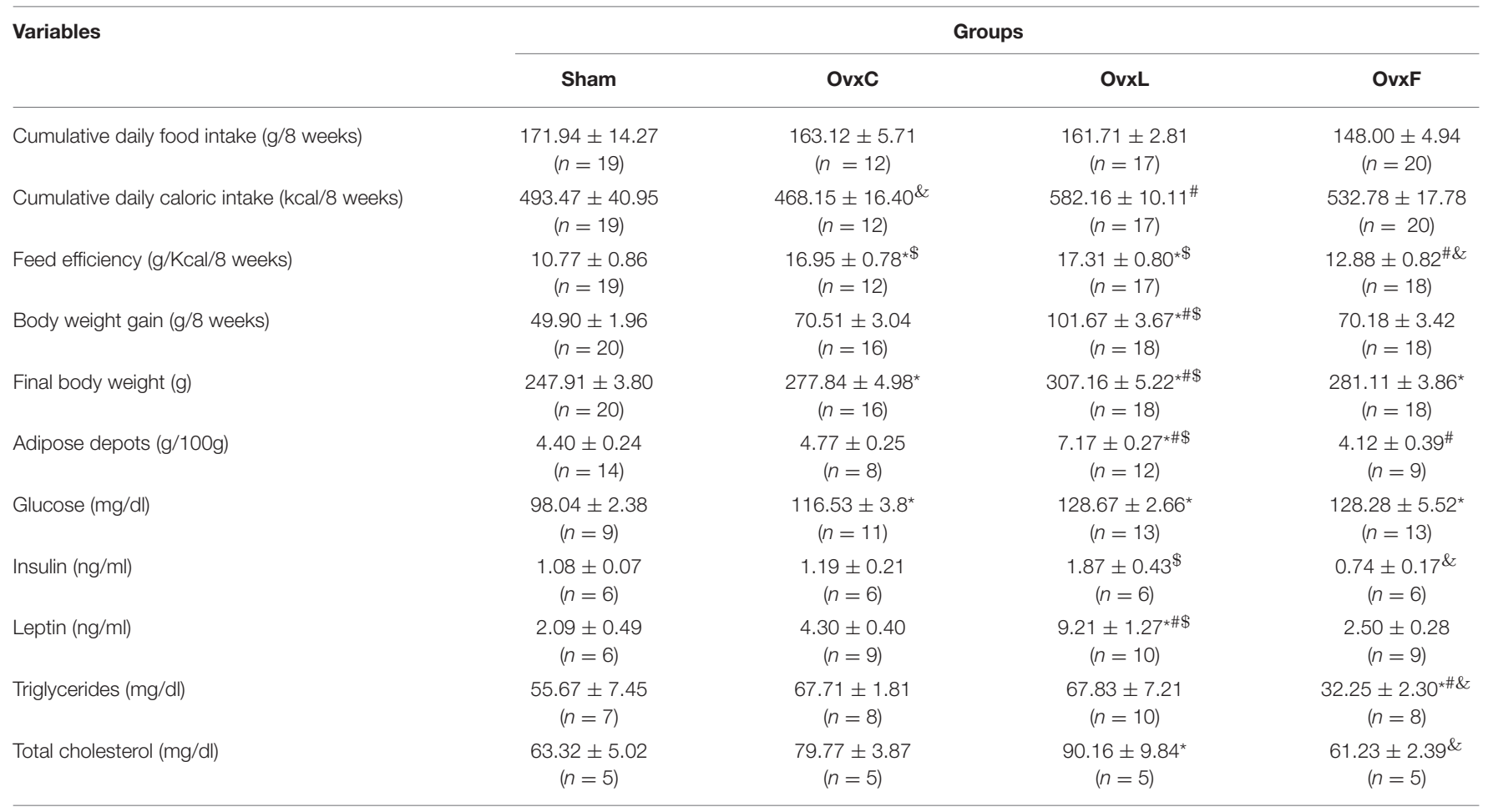

Values are Mean $\pm S E M{ }^{*} p<0.05$ vs. Sham; ${ }^{*} p<0.05$ vs. OvxC; ${ }^{\&} p<0.05$ vs. OvxL; ${ }^{\$} p<0.05$ vs. OvxF.

TABLE 2 | Catecholamines, serotonin and metabolites levels of the Sham OvxC, OvxL, and OvxF groups.

\begin{tabular}{|c|c|c|c|c|}
\hline Variables & \multicolumn{4}{|c|}{ Groups } \\
\hline 5-HT (pg/ml) & $607.81 \pm 68.54$ & $600.06 \pm 25.32$ & $558.73 \pm 44.55$ & $466.59 \pm 34.95$ \\
\hline 5-HIAA (pg/ml) & $10.38 \pm 0.36$ & $10.09 \pm 1.32$ & $8.33 \pm 0.26$ & $8.96 \pm 1.06$ \\
\hline \multicolumn{5}{|l|}{ HYPOTHALAMUS } \\
\hline Adrenaline (pg/g) & $12.17 \pm 0.87$ & $11.43 \pm 0.59$ & $14.21 \pm 1.64$ & $14.23 \pm 1.59$ \\
\hline L-Dopa (pg/g) & $6.03 \pm 1.22$ & $6.20 \pm 0.86$ & $7.55 \pm 0.88$ & $6.036 \pm 0.96$ \\
\hline Dopamine (pg/g) & $101.54 \pm 10.29$ & $102.85 \pm 4.46$ & $117.86 \pm 11.14$ & $110.50 \pm 9.04$ \\
\hline 5-HIAA (pg/g) & $290.64 \pm 43.54$ & $317.66 \pm 18.24$ & $365.95 \pm 43.96$ & $420.43 \pm 33.00$ \\
\hline 5-HT (pg/g) & $160.14 \pm 18.29$ & $192.93 \pm 3.10$ & $215.85 \pm 23.11$ & $180.17 \pm 11.20$ \\
\hline 5-HIAA/5-HT & $1.83 \pm 0.20$ & $1.66 \pm 0.12$ & $1.72 \pm 0.11$ & $2.36 \pm 0.22$ \\
\hline L-Dopa (pg/g) & $0.95 \pm 0.23$ & $0.87 \pm 015$ & $1.27 \pm 0.24$ & $1.89 \pm 0.23^{* \#}$ \\
\hline Dopamine (pg/g) & $3.30 \pm 0.49$ & $3.31 \pm 0.63$ & $3.40 \pm 0.68$ & $4.73 \pm 1.04$ \\
\hline 5-HIAA (pg/g) & $147.31 \pm 12.13$ & $163.32 \pm 8.33$ & $166.04 \pm 9.15$ & $187.27 \pm 7.56^{\star}$ \\
\hline 5-HT (pg/g) & $89.84 \pm 9.37$ & $106.79 \pm 5.28$ & $103.63 \pm 4.91$ & $87.61 \pm 5.77$ \\
\hline 5-HIAA/5HT & $1.69 \pm 0.18$ & $1.55 \pm 0.10$ & $1.60 \pm 0.10$ & $2.18 \pm 0.21^{\#}$ \\
\hline
\end{tabular}

Values are mean \pm SEM $n=5-6 .{ }^{*} p<0.05$ vs. Sham; ${ }^{*} p<0.05$ vs. OvxC. 


\section{Ovariectomy Plus High-Lard Feeding Impairs Hypothalamic Serotonergic System Gene Expression}

Hypothalamic and hippocampal mRNA levels of several genes related to metabolic and behavioral homeostasis were determined and are presented in Tables 3, 4 .

As shown in Table 3, OvxL had lower 5- $\mathrm{HT}_{1 \mathrm{~B}}$ hypothalamic gene expression $\left[F_{(3,15)}=5.042, p=0.017\right]$ than Sham $(p=$ 0.017 ) while $5-\mathrm{HT}_{2 \mathrm{C}}$ expression was higher in OvxC and $\mathrm{OvxF}$ ( $p=0.018$ and $p=0.021$, respectively) when compared to the Sham group $\left[F_{(3,15)}=5.767, p=0.011\right]$. AgRP expression was lower in $\operatorname{OvxL}$ and $\operatorname{OvxF}(p=0.018$ and $p=0.029$, respectively)

TABLE 3 | Hypothalamic gene expression of Sham, OvxC, OvxL, and OvxF animals.

\begin{tabular}{lcccc}
\hline \multirow{2}{*}{ Genes } & \multicolumn{4}{c}{ Groups } \\
\cline { 2 - 5 } & Sham & OvxC & OvxL & OvxF \\
\hline 5-HT $1 \mathrm{~A}$ & $1.01 \pm 0.09$ & $0.79 \pm 0.09$ & $0.68 \pm 0.08$ & $0.81 \pm 0.03$ \\
$5-\mathrm{HT}_{1 \mathrm{~B}}$ & $1.00 \pm 0.03$ & $0.94 \pm 0.07$ & $0.71 \pm 0.03^{*}$ & $0.94 \pm 0.06$ \\
5-HT $2 \mathrm{C}$ & $1.01 \pm 0.10$ & $1.55 \pm 0.13^{\star}$ & $1.26 \pm 0.04$ & $1.53 \pm 0.12^{*}$ \\
$5-\mathrm{HTT}$ & $1.07 \pm 0.15$ & $0.98 \pm 0.13$ & $0.63 \pm 0.11$ & $1.06 \pm 0.10$ \\
POMC & $1.04 \pm 0.19$ & $1.41 \pm 0.23$ & $1.36 \pm 0.10$ & $1.02 \pm 0.10$ \\
CART & $1.03 \pm 0.15$ & $1.03 \pm 0.11$ & $1.19 \pm 0.11$ & $1.12 \pm 0.09$ \\
NPY & $1.00 \pm 0.07$ & $0.93 \pm 0.05$ & $0.89 \pm 0.05$ & $0.90 \pm 0.06$ \\
AgRP & $1.01 \pm 0.11$ & $0.76 \pm 0.17$ & $0.47 \pm 0.04^{*}$ & $0.51 \pm 0.02^{*}$ \\
AdipoR1 & $1.00 \pm 0.03$ & $1.09 \pm 0.06$ & $1.04 \pm 0.02$ & $1.10 \pm 0.07$ \\
AdipoR2 & $1.00 \pm 0.01$ & $0.86 \pm 0.03$ & $0.85 \pm 0.05$ & $0.79 \pm 0.02^{*}$ \\
ObR & $1.00 \pm 0.06$ & $1.07 \pm 0.04$ & $0.81 \pm 0.11$ & $0.90 \pm 0.01$
\end{tabular}

The mRNA levels were measured by RT-PCR and expression of the target genes was normalized against that of the Sham animals.

Values are mean \pm SEM $n=5-6$. The housekeeping gene $\beta$-actin mRNA was used to normalize the relative amounts of mRNA. ${ }^{*} p<0.05$ vs. Sham.

TABLE 4 | Hippocampal gene expression of Sham, OvxC, OvxL, and OvxF animals.

\begin{tabular}{lcccc}
\hline Genes & \multicolumn{4}{c}{ Groups } \\
\cline { 2 - 5 } & Sham & OvxC & OvxL & OvxF \\
\hline 5-HT $1 \mathrm{~A}$ & $1.02 \pm 0.12$ & $0.96 \pm 0.15$ & $0.91 \pm 0.09$ & $0.80 \pm 0.08$ \\
$5-\mathrm{HT}_{1 \mathrm{~B}}$ & $1.04 \pm 0.17$ & $1.05 \pm 0.06$ & $1.16 \pm 0.06$ & $0.96 \pm 0.10$ \\
$5-\mathrm{HT}$ 2C & $1.00 \pm 0.04$ & $0.98 \pm 0.16$ & $1.50 \pm 0.27$ & $1.35 \pm 0.19$ \\
$5-\mathrm{HTT}$ & $1.20 \pm 0.40$ & $0.79 \pm 0.13$ & $0.78 \pm 0.18$ & $0.76 \pm 0.09$ \\
POMC & $1.01 \pm 0.10$ & $1.43 \pm 0.21$ & $0.90 \pm 0.09$ & $1.36 \pm 0.12$ \\
CART & $1.07 \pm 0.23$ & $1.17 \pm 0.21$ & $1.15 \pm 0.25$ & $1.14 \pm 0.22$ \\
NPY & $1.00 \pm 0.01$ & $0.95 \pm 0.09$ & $1.09 \pm 0.13$ & $0.99 \pm 0.06$ \\
AgRP & $1.01 \pm 0.10$ & $0.88 \pm 0.08$ & $0.89 \pm 0.09$ & $1.12 \pm 0.10$ \\
AdipoR1 & $1.00 \pm 0.01$ & $0.94 \pm 0.02$ & $1.09 \pm 0.08$ & $1.14 \pm 0.11$ \\
AdipoR2 & $1.00 \pm 0.04$ & $0.83 \pm 0.04$ & $0.94 \pm 0.10$ & $0.77 \pm 0.05$ \\
ObR & $1.02 \pm 0.12$ & $1.06 \pm 0.17$ & $1.21 \pm 0.20$ & $1.02 \pm 0.02$
\end{tabular}

The mRNA levels were measured by RT-PCR and expression of the target genes was normalized against that of the Sham animals.

Values are mean \pm SEM $n=5-6$. The housekeeping gene $\beta$-actin mRNA was used to normalize the relative amounts of $m R N A$. than in Sham rats $\left[F_{(3,15)}=5.458, p=0.013\right]$. AdipoR2 gene expression $\left[F_{(3,15)}=5.847, p=0.011\right]$ was lower in OvxF than in Sham animals $(p=0.008)$.

These data show that the intake of lard or fish-oil by the ovariectomized rats affected distinctly the components of the hypothalamic serotonergic system. While the effect of the lard diet pointed to a deleterious consequence on the serotonergic effectiveness, both ovariectomy alone or combined with fish-oil intake tended to yield to an upregulation of serotonin action.

No significant changes were found in hippocampal gene expression among the groups (Table 4).

\section{Fish Diet Reverses the Ovariectomy-Induced Impairment of Serotonin Hypophagia}

In order to analyze the hypophagic effect of intracerebroventricular serotonin after ovaries removal and chronic consumption of different high-fat diets, the animals received 200 or $300 \mu \mathrm{g}$ of serotonin ICV. The results are shown in Figure 1.

The ICV injection of $200 \mu \mathrm{g}$ of serotonin had no effect on food intake (data not shown). The dose of $300 \mu \mathrm{g}$ of serotonin evoked a significant hypophagic effect on Sham animals in the first period of $12 \mathrm{~h}(p=0.026)$ and in the cumulative period of $24 \mathrm{~h}$ ( $p=$ 0.025). In addition, OvxF presented a significant decrement of food intake in the second period of $12 \mathrm{~h}(p=0.009)$ and in the cumulative period of $24 \mathrm{~h}(p=0.007)$ after serotonin injection. Contrastingly, serotonin failed to significantly inhibit feeding in OvxC and OvxL animals.

These findings show that ovariectomy suppressed the ability of central serotonin to inhibit food intake. The use of the fish-oil diet, but not of the lard diet by the ovariectomized rats restored serotonin hypophagia.

\section{Either High-Fat Diet Reversed the Anxiogenic Effect of Ovariectomy}

The anxiety-like behavior was assessed in the elevated plus maze test, which is based on the conflict between exploration of the environment and the fear of the potential danger resulting from this exposure (Pellow et al., 1985). As illustrated in Figure 2, the OvxC animals entered fewer times $\left[F_{(3,38)}=4.843, p=0.006\right]$ (Figure 2A) and traveled a shorter distance in the open arms $\left[F_{(3,38)}=3.881, p=0.017\right]$ (Figure 2B) than the Sham rats $(p$ $=0.005$ e $p=0.013$, respectively). Moreover, OvxC also spent less time exploring the open arms $\left[F_{(3,38)}=5.025, p=0.005\right]$ and more time in the closed arms $\left[F_{(3,38)}=6.063, p=0.002\right]$ when compared to both Sham and OvxF groups $(p=0.003$ and $p=0.006$, respectively) (Figure 2C). There were no significant differences among the groups regarding the number of entries and the distance traveled in the closed arms (Figures 2A,B, respectively). As shown in Figure 2D, OvxC presented higher anxiety index $\left[F_{(3,38)}=5.128, p=0.05\right]$ when compared to Sham $(p=0.012)$ and $\operatorname{OvxF}(p=0.006)$ animals.

These findings show that ovariectomy induced an anxietylike behavior, evidenced by lower exploration of the open spaces of the maze. However, high-fat diets consumption, independent 


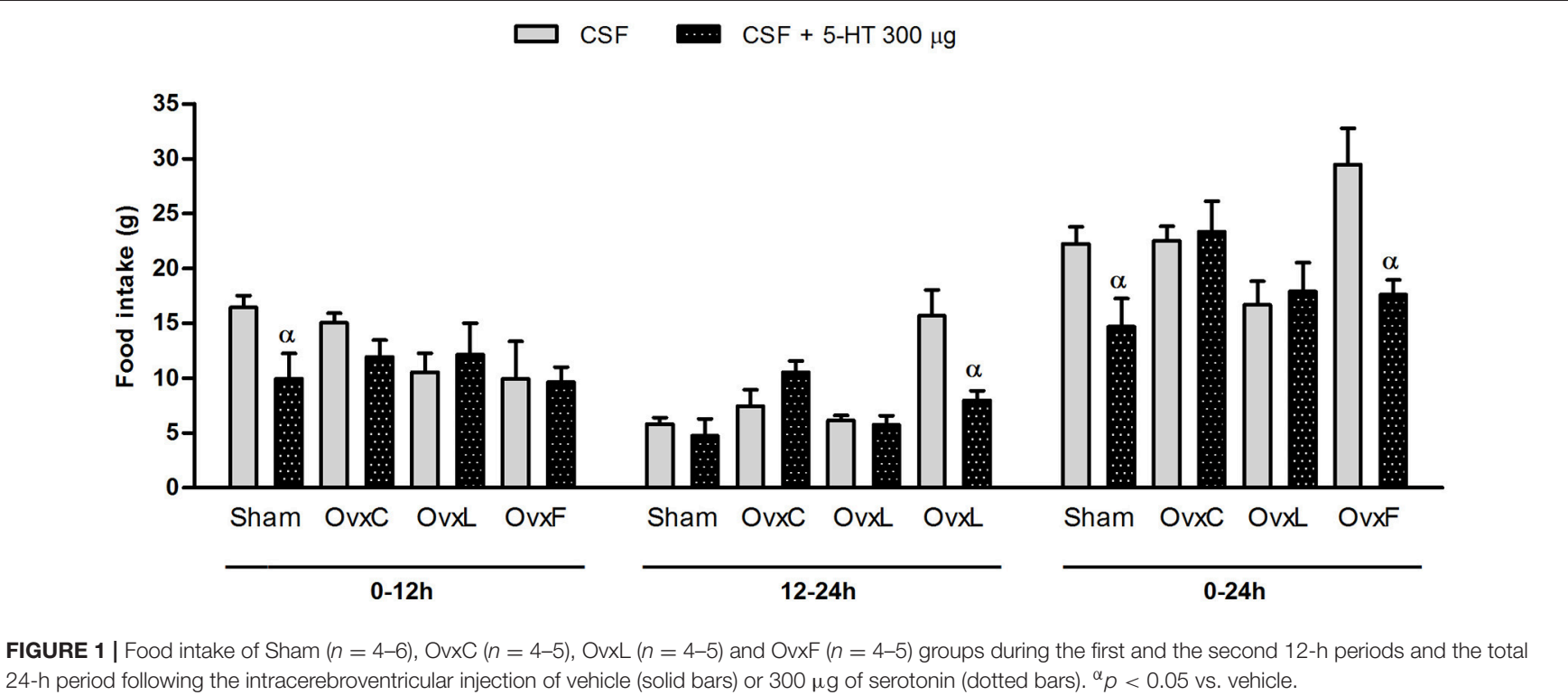

24-h period following the intracerebroventricular injection of vehicle (solid bars) or $300 \mu \mathrm{g}$ of serotonin (dotted bars). ${ }^{\alpha} p<0.05 \mathrm{vs}$. vehicle.
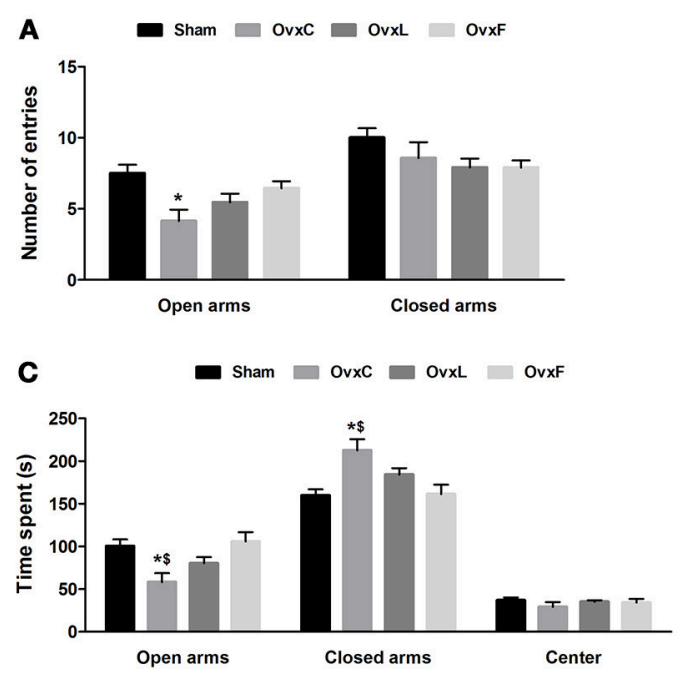

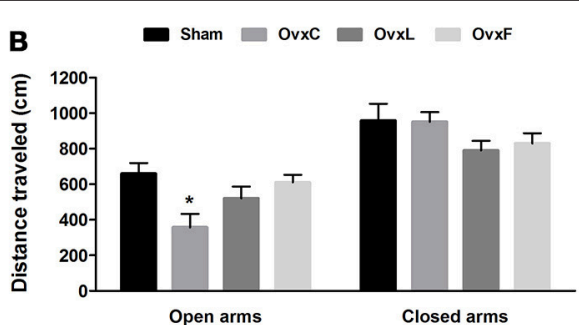

D

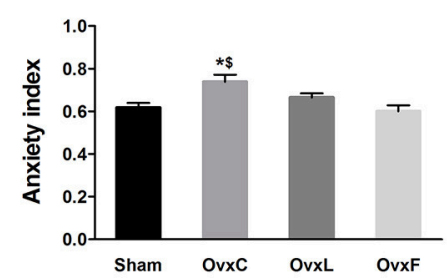

FIGURE 2 | Number of entries (A), distance (B), and percentage of time spent (C) in the open or closed arms, and anxiety index (D) during the elevated plus maze test of Sham $(n=12), \operatorname{OvxC}(n=8), \operatorname{OvxL}(n=9)$, and $\operatorname{OvxF}(n=11)$ rats. ${ }^{*} p<0.05$ vs. Sham; $\$ p<0.05$ vs. OvxF.

of the fatty acids type, reverted this anxiogenic effect of ovariectomy.

\section{Ovariectomy Allied to High-Lard Intake Induced Depressive-Like Behavior}

The depressive-like behavior was assessed by the forced swimming test, in which the frequency of immobility is considered the main indicative of depressive-like state (Porsolt et al., 1977). There were no significant differences in swimming (Figure 3A), climbing (Figure 3B), and immobility frequencies (Figure 3C) among the groups. However, the OvxL group showed a non-significant decrement of swimming frequency when compared to the Sham group $(p=0.528)$. As illustrated in Figure 3D, the latency to immobility was shorter in the OvxL group $\left[F_{(3,41)}=3.920, p=0.016\right]$ than in the Sham group $(p=$ 0.028 ). These results indicate that ovariectomy allied to high-lard intake induced vulnerability to a depressive-like state.

\section{AgRp Gene Expression Associations Indicate Beneficial Effects on Depression and Anxiety Measures}

The correlation analyses were performed to determine the associations between behavioral and metabolic variables. The following parameters were included in the correlation analysis: all parameters of the elevated plus maze test and of the forced swimming test, body weight gain, adipose depots mass and their 
A

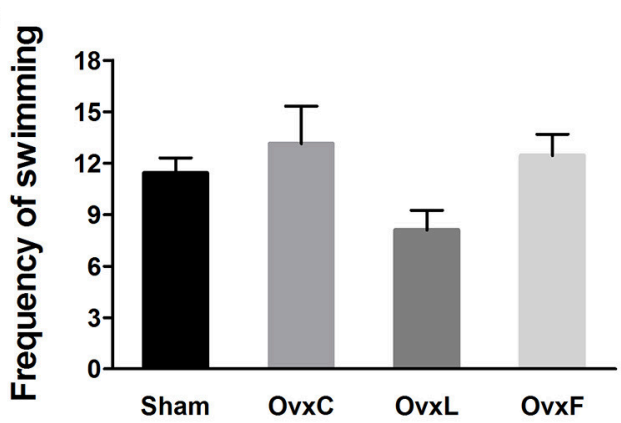

C

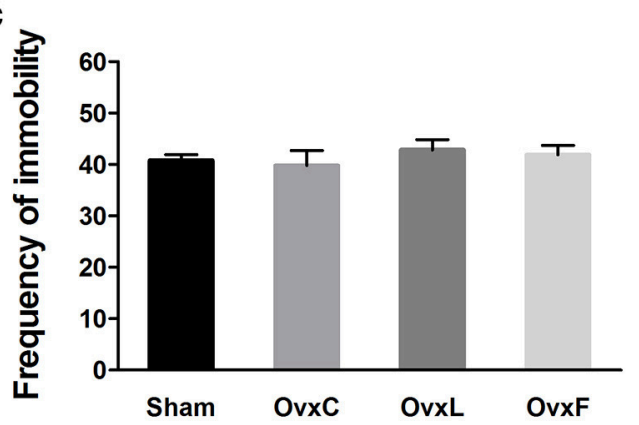

\section{B}

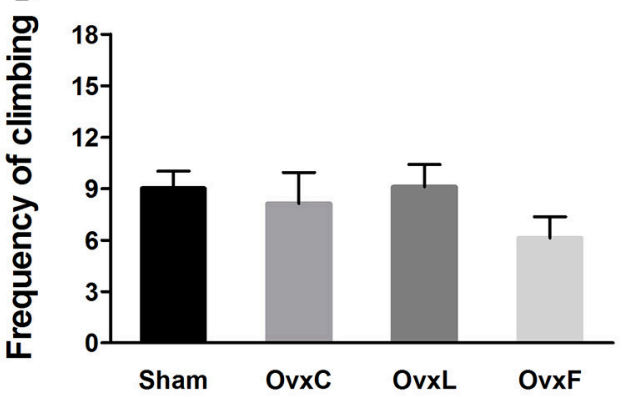

D

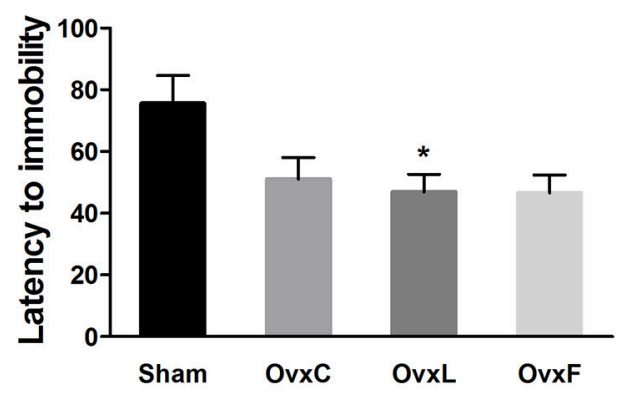

FIGURE 3 | Swimming (A), climbing (B), immobility frequencies (C), and latency to immobility (D) of Sham ( $n=14)$, OvxC $(n=8), \operatorname{OvxL}(n=12)$, and OvxF $(n=9)$ rats during the forced swim test. ${ }^{\star} p<0.05$ vs. Sham.

TABLE 5 | Pearson's correlation coefficients of the Sham, OvxC, OvxL, and OvxF groups.

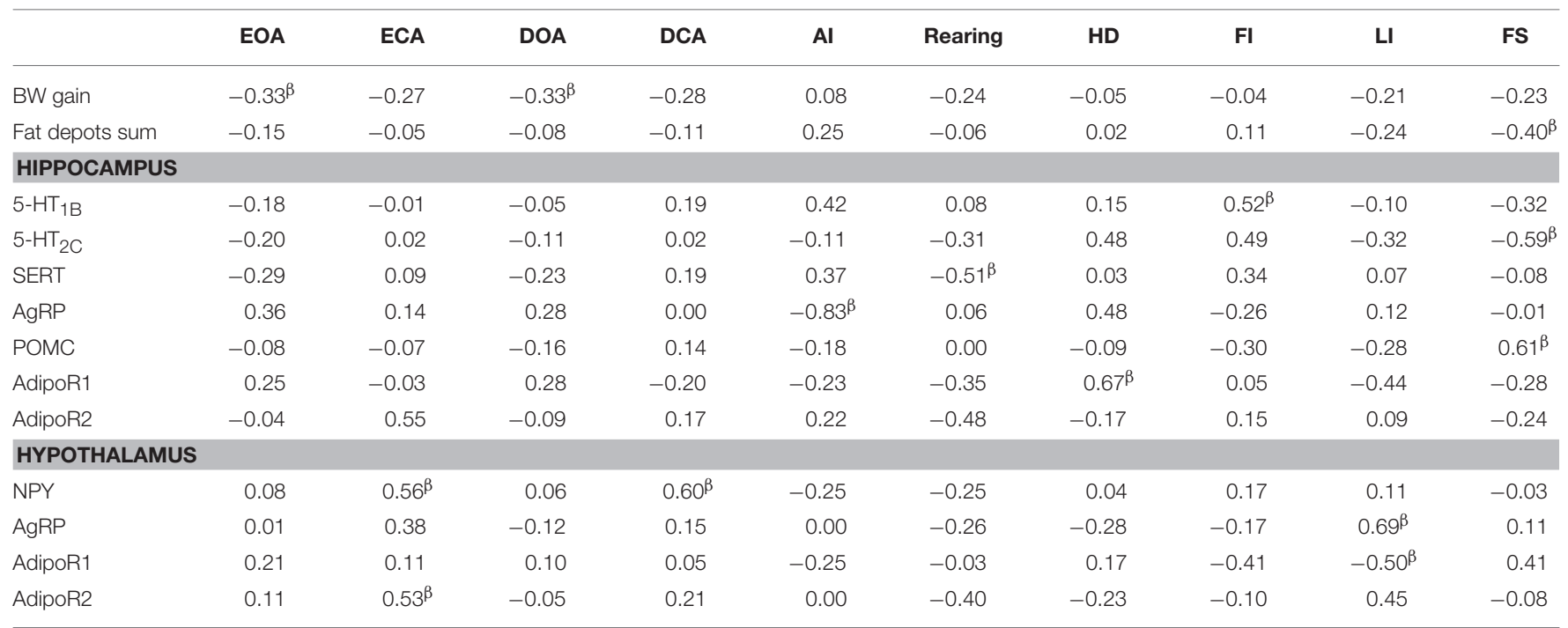

Pearson's correlation coefficients between behavioral body adiposity and gene expression parameters $(n=15-16)$.

EOA, number of entries in open arms; ECA, number of entries in closed arms; DOA, distance traveled in open arms; DCA, distance traveled in closed arms; Al, anxiety index; HD, headdipping; Fl, frequency of immobility; Ll, latency of immobility; FS, frequency of swimming. ${ }^{\beta} p<0.05$.

sum, and all genes expression data. Table 5 depicts the variables showing at least one significant correlation.

In the elevated plus maze test, the number of entries in the open arms presented an inverse correlation with the total body weight gain $(p=0.040)$, while the number of entries in the closed arms showed direct associations with hypothalamic gene expression of NPY $(p=0.025)$ and AdipoR2 $(p=0.033)$. The distance traveled in the open arms had an inverse association with body weight gain $(p=0.045)$ while the distance traveled in the closed arms showed a direct correlation with NPY hypothalamic gene expression $(p=0.014)$. The anxiety index presented an inverse correlation with hippocampal AgRP expression ( $p=$ 0.004). Rearing behavior had a negative association to SERT expression in hippocampus $(p=0.042)$ while the number 
TABLE 6 | Linear regression models for predictors of behavioral parameters.

\begin{tabular}{lccl}
\hline Predictors & \multicolumn{1}{c}{ Beta coefficients } & Standard error & $\boldsymbol{p}$-value \\
\hline DEPENDENT VARIABLE: ANXIETY INDEX & & \\
AgRP hpc & -0.34 & 0.06 & $8.11^{-5}$ \\
Intercept & 0.95 & 0.06 & $3.72^{-10}$ \\
DEPENDENT VARIABLE: FREQUENCY OF IMMOBILITY & \\
$5-H T_{1 B} h p c$ & 11.46 & 4.99 & 0.037 \\
Intercept & 30.80 & 5.38 & $5.27^{-5}$ \\
DEPENDENT VARIABLE: LATENCY TO IMMOBILITY & \\
AgRP hpt & 58.81 & 17.15 & 0.004 \\
Intercept & 11.97 & 12.06 & 0.33 \\
\hline
\end{tabular}

hpc, hippocampus; hpt, hypothalamus.

of headdippings was positively related to AdipoR1 gene in hippocampus $(p=0.005)$.

In the forced swimming test, the frequency of immobility presented a direct association with $5-\mathrm{HT}_{1 \mathrm{~B}}$ hippocampal gene expression $(p=0.038)$ while the latency to immobility had a positive association with hypothalamic $\operatorname{AgRP}(p=0.004)$ and a negative association with hypothalamic AdipoR1 $(p=0.0 .46)$. The frequency of swimming had an inverse correlation with the sum of adipose depots $(p=0.008)$ and with hippocampal $5-\mathrm{HT}_{2 \mathrm{C}}$ $(p=0.017)$, and a direct association with hippocampal POMC gene $(p=0.012)$.

These results showed associations of hippocampal and hypothalamic gene expression rates with behavioral measures indicative of anxious-like and depressive-like behaviors. We then used linear regression models to identify predictors for the variations of the behavioral parameters anxiety index, frequency of immobility and latency to immobility, among the hypothalamic and hippocampal genes presenting significant correlation with these behavioral parameters (Table 6).

For the anxiety index, the model predicted $68 \%$ of the variations $\left[R=0.85, R^{2}=0.68, F_{(1,14)}=30.024, p<0.00008\right]$ and showed that hippocampal $\operatorname{AgRP}\left(p=3.01^{-5}\right)$ was a negative predictor (power 0.9959, effect size $2.1250,2$ predictors). The other predictor tested was the hippocampal $5-\mathrm{HT}_{1 \mathrm{~B}}$ serotonin receptor but its effect was not significant.

The linear regression model for frequency to immobility in the forced swimming test predicted $27 \%$ of the variations $[R=$ $\left.0.52, R^{2}=0.27, F_{(1,14)}=5.270, p=0.037\right)$ and showed that hippocampal 5- $\mathrm{HT}_{1 \mathrm{~B}}$ gene expression was a positive predictor ( $p=0.037$ ) (power 0.4474 , effect size $0.3698,2$ predictors). The other predictor tested was the hippocampal $5-\mathrm{HT}_{2} \mathrm{C}$ serotonin receptor but its effect was not significant.

For the latency to immobility, the linear regression model predicted $47 \%$ of the variations $\left[R=0.68, R^{2}=0.47 F_{(1,13)}\right.$ $=11.749, p=0.004]$ and showed that hypothalamic gene expression of $\operatorname{AgRP}(p=0.004)$ was a positive predictor (power 0.8279 , effect size $0.8867,2$ predictors). The other predictor tested was the hypothalamic AdipoR1 but its effect was not significant.

Overall, the linear regression models pointed to AgRp gene expression associations indicative of a beneficial involvement of this neuropeptide on both depression and anxiety measures.

\section{DISCUSSION}

To investigate mechanisms involved in the putative interaction of metabolic disturbances and mood and anxiety disorders developed after menopause, we examined the effects of ovariectomy alone or in combination with chronic consumption of high-fat diets on metabolic/neurochemical and behavioral parameters of rats. The diets differed in their fat source by the use of either lard (rich in saturated fatty acids) or fish-oil (rich in $\mathrm{n}-3$ polyunsaturated fatty acids).

Ovariectomy induced excess body weight gain in the absence of excess food intake, probably as result of increased feed efficiency. Additionally, since previous studies in animals and humans have reported basal metabolism decrements in estrogendeficient states (Ainslie et al., 2001; Monda et al., 2006; Witte et al., 2010), this aspect, not evaluated in the present study, may have played a role.

The intake of the lard diet exacerbated the body weight gain of the ovariectomized group and increased body adiposity and leptinemia. The saturated fatty acids have the highest obesogenic ability (Buettner et al., 2006), a fact associated with its higher rate of acylation into triglycerides and lower rate of oxidation in comparison to polyunsaturated and monounsaturated fatty acids (Siddiqi et al., 2000). Chronic intake of lard-enriched diet impaired carnitine-palmitoyltransferase-1 function, damaging the mitochondrial import and oxidation of long chain fatty acids (Noland et al., 2009).

In contrast, although similar in caloric density, the fish-oil diet reduced body adiposity, tryglicerides and total cholesterol levels, and restored feed efficiency to levels similar to those of the Sham rats. Numerous studies have shown that $n-3$ polyunsaturated fatty acids present beneficial metabolic effects (Misra et al., 2010; Abeywardena and Patten, 2011; Robinson and Mazurak, 2013). In relation to their effect on adipose tissue, omega-3 fatty acids reportedly modulated gene expression through transcription factors such as peroxisome proliferatoractivated receptor $\gamma$ (PPAR $\gamma)$, resulting in the stimulus of fatty acids oxidation in mitochondria and peroxisomes (Hensler et al., 2011). Docosahexaenoic acid (DHA, 22:6n-3) and eicosapentaenoic acid (EPA, 20:5n-3) presented hypolipidemic effects, in part due to inhibition of fat cell proliferation (Ruzickova et al., 2004). Additionally, omega-3 fatty acids stimulated the generation of new mitochondria in adipocytes and activated the expression of the carnitin-palmitoyl-transferase 1 gene (Flachs and Hal, 2005).

In the present study, all ovariectomized groups presented hyperglycemia, in agreement with the disrupted glycemic control induced by estrogen deficiency (Ross and Polotsky, 2012). Inadequate glycemic control has been directly associated with depression in humans (Lustman et al., 2000). This agrees with the present findings that, although only lard intake allied to ovariectomy caused a statistically significant decrease of the latency to immobility (a measure indicative of increased propensity to develop depression), this parameter showed a relevant decrement in all ovariectomized groups. 
As expected, the intracerebroventricular administration of serotonin induced hypophagia in the Sham animals. In contrast, this effect was completely abolished in the OvxC and OvxL groups, while it was preserved in the OvxF group. Serotonin induces hypophagia by modulating the expression of the hypothalamic orexigenic and anorexigenic neuropeptides (Choi et al., 2003, 2006; Ronan and Summers, 2011; Donovan and Tecott, 2013). Serotonin binding to $5-\mathrm{HT}_{1 \mathrm{~B}}$ reportedly inhibited NPY/AgRP orexigenic neurons, while its binding to $5-\mathrm{HT}_{2} \mathrm{C}$ activated anorexigenic POMC/CART neurons (Heisler et al., 1999, 2006; Garfield and Heisler, 2009). The present results of hypothalamic gene expression showed increased expression of $5-\mathrm{HT}_{2 \mathrm{C}}$ in the OvxC and OvxF animals. In view of the lack of serotonin hypophagia in OvxC group, it can be suggested that $5-\mathrm{HT}_{2} \mathrm{C}$ upregulation may have represented a compensatory mechanism, aimed at surpassing receptor insensitivity. It is interesting that the high-fat diets affected differentially serotonin receptor expressions. The lard diet had a deleterious effect, both abolishing $5-\mathrm{HT}_{2} \mathrm{C}$ upregulation and inducing $5-\mathrm{HT}_{1 \mathrm{~B}}$ downregulation. These effects are highly consistent with the absence of serotonin hypophagia after lard intake. In contrast, although fish-oil intake induced receptor expression alterations similar to those seen in the $\mathrm{OvxC}$ group, serotonin hypophagia was maintained. The factors leading to the absence of hypophagia in OvxC, but not in OvxF, are not apparent, as $5-\mathrm{HT}_{2} \mathrm{C}$ expression was elevated in both groups. One contributing factor may derive from our previous data, in male rats, showing that fish-oil intake increased neuronal activation of hypothalamic sites expressing anorexigenic mediators, indicating a positive effect of fish oil in mobilizing multiple hypothalamic anorexigenic pathways (Watanabe et al., 2009).

The present findings showing that both metabolic and behavioral alterations were caused by ovariectomy agree with the reported homeostatic role of ovarian hormones (Humeniuk et al., 2011; Kiss et al., 2012; Messina et al., 2013). Additionally, the present demonstration of significant associations between neuropeptides and serotonin receptors with behavioral parameters highlight the existence of a complex connection between them.

The intake of either the lard or the fish-oil diet normalized the anxiety index of the Ovx animals, indicating an anxiolytic effect of the high-fat diets, regardless the fatty acid composition. A previous report showed that myristic acid (C16:0) produced anxiolytic-like effects comparable to those of diazepam in male rats (Contreras et al., 2014). We have previously reported myristic acid as the most abundant fatty acid in the lardenriched diet consumed by our animals (Dornellas et al., 2015). It has been shown that palatable foods, such as diets rich in sugar and lard, reduced signs of stress and anxiety in humans and animals (Finger et al., 2011; Singh, 2014). Furthermore, OvxF rats had higher hippocampal concentrations of L-Dopa and 5-HIAA and elevated serotonin turnover when compared to the Sham rats. In accordance, it has been reported that supplementation with fish oil reversed the reduced hippocampal serotonin level in mice under chronic mild stress (Vancassel et al., 2008), indicating an anxiolytic effect of fish oil, probably mediated by stimulated serotonergic activity.

Serotonergic neurons play an important role in mood disorders and serotonin deficiency is known to be a substantial contributing factor in anxiety and depression (Brigitta, 2002; Leonardo and Hen, 2006; Kormos and Gaszner, 2013). The present data showed hippocampal $5-\mathrm{HT}_{1 \mathrm{~B}}$ gene to be a positive predictor of the frequency of immobility during the forced swimming test, a paradigm of depressive-like behavior in rats. The $5-\mathrm{HT}_{1 \mathrm{~B}}$ receptor inhibits serotonin release acting as an auto-receptor in serotonergic neurons and as a heteroreceptor in hippocampal gabaergic neurons (Clark et al., 2006; López-Pantoja et al., 2012). Mice lacking 5-HT $1 \mathrm{~B}$ autoreceptors displayed increased extracellular serotonin levels in the ventral hippocampus, following the administration of a selective serotonin reuptake inhibitor, and decreased anxietylike behavior and antidepressant-like effects in the forced swim and sucrose preference tests (Nautiyal et al., 2016). Additionally, estrogen replacement induced an antidepressantlike action in ovariectomized rats, but this effect did not occur in animals with destruction of serotonergic innervation (VegaRivera et al., 2013). These data show that $5-\mathrm{HT}_{1 \mathrm{~B}}$ activity decreases serotonergic activity and support the present finding of this receptor as a positive predictor of depression, as observed in OvxL animals.

The present experiments indicated the possible involvement AgRP neuropeptide in modulating both anxious- and depressivelike behaviors. The linear regression model found AgRP gene expression in hippocampus to be a negative predictor of the anxiety index. Additionally, hypothalamic AgRP expression was a positive predictor of the latency to immobility. The latter finding is in agreement with the present observation of decreased hypothalamic AgRP and latency to immobility by ovariectomy allied to high-fat saturated diet. Little is known about the influence of neuropeptides regulating energy homeostasis on emotional behaviors. Importantly, reduction of AgRP signaling increased extracellular dopamine levels in the basal forebrain, leading to increased exploratory behavior and response to cocaine (Dietrich et al., 2012). Moreover, brain AgRP infusion reduced locomotor activity (Tang-Christensen et al., 2004). The present results add relevant information to the understanding of the influence of hypothalamic neuropeptides on nonfoodassociated behaviors, indicating a possible involvement of AgRP on emotional disruption mechanisms leading to the anxiety and depression states observed after menopause. Further experiments are required to verify the role played by AgRP as a modulator of anxious- and depressive-like behaviors.

The present findings contributed to the characterization of the metabolic, neurochemical and behavioral changes induced by ovarian failure and demonstrated the effects of diet manipulations, highlighting a positive effect of high-fat feeding on the anxiety-like behavior shown by ovariectomized animals. Since the polyunsaturated omega-3 intake (fish diet), unlike the saturated fat intake (lard diet), failed to induce deleterious metabolic or neurochemical consequences, further studies are needed focusing on the potential of this dietary component as an adjuvant anxiolytic agent after menopause. 


\section{AUTHOR CONTRIBUTIONS}

$\mathrm{AD}$ conception and design, interpretation of data; drafting and revising it critically; final approval of the work, in agreement to be accountable for all aspects of the study. VB conceptualization, design, execution, and interpretation of the research study. LC conceptualization, execution, and interpretation of the research study. IdA conceptualization, design, execution, and or interpretation of the research study. AP conceptualization and interpretation of the research study. TV-F design, execution, and interpretation of the research study. CdS execution, and interpretation of the research study. LO revising the study critically for important intellectual content, final approval of the version to be published. CdN revising the study critically for important intellectual content, final approval of the version to be published. ER conception and design, interpretation of data; drafting and revising it critically; final approval of the work, in agreement to be accountable for all aspects of the study.

\section{REFERENCES}

Anderson, R. J., Freedland, K. E., Clouse, R. E., and Lustman P. J. (2001) The prevalence of comorbid depression in adults with diabetes: a meta-analytic review of the literature. Diab. Care 24, 1069-1078. doi: 10.2337/diacare.24.6.1069

Abeywardena, M. Y., and Patten, G. S. (2011). Role of $\omega 3$ longchain polyunsaturated fatty acids in reducing cardio-metabolic risk factors. Endocr. Metab. Immune Disord. Drug Targets. 11, 232-246. doi: $10.2174 / 187153011796429817$

Ainslie, D. A., Morris, M. J., Wittert, G., Turnbull, H., Proietto, J., and Thorburn, A. W. (2001). Estrogen deficiency causes central leptin insensitivity and increased hypothalamic neuropeptide Y. Int. J. Obes. Relat. Metabol. Disord. 25, 1680-1688. doi: 10.1038/sj.ijo.0801806

Alexander, J. L., Dennerstein, L., Kotz, K., and Richardson, G. (2007). Women anxiety and mood: a review of nomenclature comorbidity and epidemiology. Expert Rev. Neurother. 7, S45-S58. doi: 10.1586/14737175.7. 11 s.S45

Anacker, C., and Hen, R. (2017). Adult hippocampal neurogenesis and cognitive flexibility - linking memory and mood. Nat. Rev. Neurosci. 18, 335-346. doi: $10.1038 /$ nrn. 2017.45

Asarian, L., and Geary, N. (2007). Estradiol enhances cholecystokinin-dependent lipid-induced satiation and activates estrogen receptor-alpha-expressing cells in the nucleus tractus solitarius of ovariectomized rats. Endocrinology 148, 5656-5666. doi: 10.1210/en.2007-0341

Bai, F., Sözen, M. A., Lukiw, W. J., and Argyropoulos, G. (2005). Expression of AgRP, NPY, POMC and CART in human fetal and adult hippocampus. Neuropeptides 39, 439-443. doi: 10.1016/j.npep.2005.02.007

Barandas, R., Landgraf, D., McCarthy, M. J., and Welsh, D. K. (2015). Circadian clocks as modulators of metabolic comorbidity in psychiatric disorders. Curr. Psychiatry Rep. 17:98. doi: 10.1007/s11920-015-0637-2

Bebbington, P., Dunn, G., Jenkins, R., Lewis, G., Brugha, T., and Farrell, M. (2003). The influence of age and sex on the prevalence of depressive conditions: report from the national survey of psychiatric morbidity. Int. Rev. Psychiatr. 15, 74-83. doi: 10.1080/0954026021000045976

Brigitta, B. (2002). Pathophysiology of depression and mechanisms of treatment. Dialog. Clin. Neurosci. 4, 7-20.

Bromberger, J. T., and Kravitz, H. M. (2011). Mood and menopause: findings from the Study of Women's Health Across the Nation (SWAN) over 10 years. Obstet. Gynecol. Clin. North Am. 38, 609-625. doi: 10.1016/j.ogc.2011. 05.011

Buettner, R., Parhofer, K. G., Woenckhaus, M., Wrede, C. E., Kunz-Schughart, L. A., Schölmerich, J., et al. (2006). Defining high-fat-diet rat models: metabolic

\section{FUNDING}

This study was supported by grants from: the State of Sao Paulo Research Foundation (FAPESP, Brazil), the National Council for Scientific and Technological Development (CNPq, Brazil), the Coordination for the Improvement of Higher Education Personnel (Capes, Brazil), Fundação de Amparo à Pesquisa do Estado de São Paulo-FAPESP, Grants No. 2012/03172-4 and the Conselho Nacional de Desenvolvimento Científico e Tecnológico-CNPq, Grants No. 309405/2013-0 and 453924/2014-0.

\section{ACKNOWLEDGMENTS}

The authors thank Marcos Vinicius Bunscheit for technical assistance in the behavioral experiments, Dr. Lys Angela Favaroni Mendes and Dr. Dulce Elena Casarini for HPLC analysis and Dr. Deborah Suchecki for critical reading of the manuscript.

and molecular effects of different fat types. J. Mol. Endocrinol. 36, 485-501. doi: 10.1677/jme.1.01909

Campos, A. C., Fogaça, M. V., Aguiar, D. C., and Guimarães, F. S. (2013). Animal models of anxiety disorders and stress. Rev. Brasil. Psiquiat. 35 (Suppl. 2), S101-S111. doi: 10.1590/1516-4446-2013-1139

Carr, M. C. (2003). The emergence of the metabolic syndrome with menopause. J. Clin. Endocrinol. Metab. 88, 2404-2411. doi: 10.1210/jc.2003-030242

Choi, S., Blake, V., Cole, S., and Fernstrom, J. D. (2006). Effects of chronic fenfluramine administration on hypothalamic neuropeptide mRNA expression. Brain Res. 1087, 83-86. doi: 10.1016/j.brainres.2006.02.129

Choi, S. H., Kwon, B. S., Lee, S., Houpt, T. A., Lee, H. T., Kim, D. G., et al. (2003). Systemic 5-hydroxy-L-tryptophan down-regulates the arcuate CART mRNA level in rats. Regul. Pept. 115, 73-80. doi: 10.1016/S0167-0115(03) 00126-5

Clark, M. S., McDevitt, R. A., and Neumaier, J. F. (2006). Quantitative mapping of tryptophan hydroxylase-2, 5- T1A, 5-HT1B, and serotonin transporter expression across the anteroposterior axis of the rat dorsal and median raphe nuclei. J. Comp. Neurol. 498, 611-623. doi: 10.1002/cne.21073

Contreras, C. M., Rodríguez-Landa, J. F., García-Ríos, R. I., Cueto-Escobedo, J., Guillen-Ruiz, G., and Bernal-Morales, B. (2014). Myristic acid produces anxiolytic-like effects in Wistar rats in the elevated plus maze. Biomed. Res. Int. 2014:492141. doi: 10.1155/2014/492141

Correia, J., and Ravasco, P. (2014). Weight changes in Portuguese patients with depression: which factors are involved? Nutr. J. 13:117. doi: 10.1186/1475-2891-13-117

Davidson, T. L., Kanoski, S. E., Walls, E. K., and Jarrard, L. E. (2005). Memory inhibition and energy regulation. Physiol. Behav. 86, 731-46. doi: 10.1016/j.physbeh.2005.09.004

de la Iglesia, R., Loria-Kohen, V., Zulet, M. A., Martinez, J. A., Reglero, G., and Ramirez de Molina, A. (2016). Dietary strategies implicated in the prevention and treatment of metabolic syndrome. Int. J. Mol. Sci. 17:E1877. doi: 10.3390/ijms17111877

Dietrich, M. O., Bober, J., Ferreira, J. G., Tellez, L. A., Mineur, Y. S., Souza, D. O., et al. (2012). AgRP neurons regulate development of dopamine neuronal plasticity and nonfood-associated behaviors. Nat. Neurosci. 15, 1108-1110. doi: $10.1038 / \mathrm{nn} .3147$

Donovan, M. H., and Tecott, L. H. (2013). Serotonin and the regulation of mammalian energy balance. Front. Neurosci. 7:36. doi: 10.3389/fnins.2013.00036.

Dornellas, A. P. S., Watanabe, R. L. H., and Pimentel, G. D. (2015). Deleterious effects of high-lard diet on tissues fatty acids composition and hypothalamic insulin actions. Prostaglandins Leukot. Essent. Fatty Acids 102-103, 21-29. doi: 10.1016/j.plefa.2015.10.003 
Ferrer-Lorente, R., Fernández-López, J. A., Alemany, M., and Cabot, C. (2009). Short-term oral oleoyl-estrone decreases the expression of ghrelin in the rat stomach. Regul. Pept. 152, 79-81. doi: 10.1016/j.regpep.2008.09.004

Finger, B. C., Dinan, T. G., and Cryan, J. F. (2011). High-fat diet selectively protects against the effects of chronic social stress in the mouse. Neuroscience 192, 351-360. doi: 10.1016/j.neuroscience.2011.06.072

Flachs, P., and Hal, F. (2005). Polyunsaturated fatty acids of marine origin upregulate mitochondrial biogenesis and induce $\beta$-oxidation in white fat. Diabetologia 48, 2365-2375. doi: 10.1007/s00125-005-1944-7

Garfield, A. S., and Heisler, L. K. (2009). Pharmacological targeting of the serotonergic system for the treatment of obesity. J. Physiol. 587, 49-60. doi: 10.1113/jphysiol.2008.164152

Gerozissis, K. (2008). Brain insulin energy and glucose homeostasis; genes environment and metabolic pathologies. Eur. J. Pharmacol. 585, 38-49. doi: 10.1016/j.ejphar.2008.01.050

Hankin, B. L., Mermelstein, R., and Roesch, L. (2007). Sex differences in adolescent depression: stress exposure and reactivity models. Child Dev. 78, 279-295. doi: 10.1111/j.1467-8624.2007.00997.x

Heilig, M. (2004). The NPY system in stress, anxiety and depression. Neuropeptides 38, 213-224. doi: 10.1016/j.npep.2004.05.002

Heisler, L. K., Jobst, E. E., and Sutton, G. M. (2006). Serotonin reciprocally regulates melanocortin neurons to modulate food intake. Neuron 51, 239-249. doi: 10.1016/j.neuron.2006.06.004

Heisler, L. K., Kanarek, R. B., and Homoleski, B. (1999). Reduction of fat and protein intakes but not carbohydrate intake following acute and chronic Fluoxetine in female rats. Pharmacol. Biochem. Behav. 63, 377-385. doi: 10.1016/S0091-3057(99)00021-0

Hensler, M., Bardova, K., Jilkova, Z. M., Wahli, W., Meztger, D., Chambon, P., et al. (2011). The inhibition of fat cell proliferation by $n-3$ fatty acids in dietary obese mice. Lipids Health Dis. 10:128. doi: 10.1186/1476-511X$10-128$

Humeniuk, E., Bojar, I., Owoc, A., Wojtyła, A., and Fronczak, A. (2011). Psychosocial conditioning of depressive disorders in post-menopausal women. Ann. Agric. Environ. Med. 18, 441-445.

Hunter, R. G., Bellani, R., Bloss, E., Costa, A., Romeo, R. D., and McEwen, B. S. (2007). Regulation of CART mRNA by stress and corticosteroids in the hippocampus and amygdala. Brain Res. 1152, 234-240. doi: 10.1016/j.brainres.2007.03.042

Huynh, T. N., Krigbaum, A. M., Hanna, J. J., and Conrad, C. D. (2011). Sex differences and phase of light cycle modify chronic stress effects on anxiety and depressive-like behavior. Behav. Brain Res. 222, 212-222. doi: 10.1016/j.bbr.2011.03.038

Kanoski, S. E., and Grill, H. J. (2017). Hippocampus contributions to food intake control: mnemonic, neuroanatomical, and endocrine mechanisms. Biol. Psychiatr. 81, 748-756. doi: 10.1016/j.biopsych.2015.09.011

Kask, A., Harro, J., von Hörsten, S., Redrobe, J. P., Dumont, Y., and Quirion, R. (2002). The neurocircuitry and receptor subtypes mediating anxiolyticlike effects of neuropeptide Y. Neurosci. Biobehav. Rev. 26, 259-283. doi: 10.1016/S0149-7634(01)00066-5

Kessler, R. C., Sampson, N. A., and Berglund, P. (2015). Anxious and non-anxious major depressive disorder in the World Health Organization World Mental Health Surveys. Epidemiol. Psychiatr. Sci. 1-17, 210-216. doi: 10.1017/S2045796015000189

Kim, W. K., Shin, D., and Song, W. O. (2015). Depression and its comorbid conditions more serious in women than in men in the United States. J. Womens Health. 24, 978-985. doi: 10.1089/jwh.2014.4919

Kiss, A., Delattre, A. M., and Pereira, S. I. et al. (2012). 17ß-Estradiol replacement in young adult and middle-aged female ovariectomized rats promotes improvement of spatial reference memory and an antidepressant effect and alters monoamines and BDNF levels in memory- and depressionrelated brain areas. Behav. Brain Res. 227, 100-108. doi: 10.1016/j.bbr.2011. 10.047

Kormos, V., and Gaszner, B. (2013). Role of neuropeptides in anxiety stress and depression: from animals to humans. Neuropeptides 47, 401-419. doi: 10.1016/j.npep.2013.10.014

Leonardo, E. D., and Hen, R. (2006). Genetics of affective and anxiety disorders. Annu. Rev. Psychol. 57, 117-137. doi: 10.1146/annurev.psych.57.102904.190118
Livak, K. J., and Schmittgen, T. D. (2001). Analysis of relative gene expression data using real-time quantitative PCR and the 2(-Delta Delta C(T)). Method. Methods 25, 402-408. doi: 10.1006/meth.2001.1262

López-Pantoja J. L., Cabranes, J. A., Sanchez-Quintero, S., Velao, M., Sanz, M., Torres-Pardo, B., et al. (2012). Personality profiles between obese and control subjects assessed with five standardized personality scales. Actas Esp. Psiquiatr. 40, 266-274.

Lustman, P. J., Anderson, R. J., Freedland, K. E., de Groot, M., Carney, R. M., and Clouse, R. E. (2000). Depression and poor glycemic control: a meta-analytic review of the literature. Diab. Care 23, 934-942. doi: 10.2337/diacare.23.7.934

Mahar, I., Bambico, F. R., Mechawar, N., and Nobrega, J. N. (2014). Stress, serotonin, and hippocampal neurogenesis in relation to depression and antidepressant effects. Neurosci. Biobehav. Rev. 38, 173-192. doi: 10.1016/j.neubiorev.2013.11.009

Martins, G. L., Tanaka, R. M., Campos, N. B., and Dalbosco, I. S. (2002). Prevalência de depressão em mulheres com diabetes mellitus tipo 2 na pós-menopausa. Arq. Bras. Endocrinol. Metab. 46, 674-678. doi: 10.1590/S0004-27302002000600012

Messina, G., Viggiano, A., De Luca, V., Messina, A., Chieffi, S., and Monda, M. (2013). Hormonal changes in menopause and orexin-a action. Obstet. Gynecol. Int. 2013:209812. doi: 10.1155/2013/209812

Milewicz, A., Bidzinska, B., and Sidorowicz, A. (1996). Perimenopausal obesity. Gynecol. Endocrinol. 10, 285-291. doi: 10.3109/09513599609012322

Misra, A., Singhal, N., and Khurana, L. (2010). Obesity, the metabolic syndrome, and type 2 diabetes in developing countries: role of dietary fats and oils. J. Am. Coll. Nutr. 29(Suppl. 3), 289S-301S.

Monda, M., Messina, G., Vicidomini, C., Viggiano, A., Mangoni, C., and De Luca, B. (2006). Activity of autonomic nervous system is related to body weight in pre-menopausal, but not in post-menopausal women. Nutr. Neurosci. 9, 141-145. doi: 10.1080/10284150600903552

Nautiyal, K. M., Tritschler, L., Ahmari, S. E., David, D. J., Gardier, A. M., and Hen, R. (2016). A lack of serotonin $1 \mathrm{~b}$ autoreceptors results in decreased anxiety and depression-related behaviors. Neuropsychopharmacology 41, 2941-2950. doi: $10.1038 / n p p .2016 .109$

Ng, M., Fleming, T., Robinson, M., Thomson, B., Graetz, N., Margono, C., et al. (2014). Global regional and national prevalence of overweight and obesity in children and adults during 1980-2013: a systematic analysis for the Global Burden of Disease Study 2013. Lancet 384, 766-781. doi: 10.1016/S0140-6736(14)60460-8

Noland, R. C., Koves, T. R., Seiler, S. E., Lum, H., Lust, R. M., Ilkayeva, O., et al. (2009). Carnitine insufficiency caused by aging and overnutrition compromises mitochondrial performance and metabolic control. J. Biol. Chem. 284, 22840-22852. doi: 10.1074/jbc.M109.032888

Olofsson, L. E., Pierce, A. A., and Xu, A. W. (2009). Functional requirement of AgRP and NPY neurons in ovarian cycle-dependent regulation of food intake. Proc. Natl. Acad. Sci. U.S.A. 106, 15932-15937. doi: 10.1073/pnas.0904747106

Ostwald, D., Karpac, J., and Hochqeschwender, U. (2006). Effects on hippocampus of lifelong absence of glucocorticoids in the pro-opiomelanocortin null mutant mouse reveal complex relationship between glucocorticoids and hippocampal structure and function. J. Mol. Neurosci. 28, 291-302. doi: $10.1385 / \mathrm{JMN}: 28: 3: 291$

Panza, F., Solfrizzi, V., Logroscino, G., Maggi, S., Santamato, A., Seripa, D., et al. (2012). Current epidemiological approaches to the metaboliccognitive syndrome. J. Alzheimers Dis. 30 (Suppl. 2), S31- S75. doi: 10.3233/JAD-2012-111496

Paxinos, G., Watson, C., Pennisi, M., and Topple, A. (1985). Bregma lambda and the interaural midpoint in stereotaxic surgery with rats of different sex strain and weight. J. Neurosci. Methods 13, 139-143. doi: 10.1016/0165-0270(85)90026-3

Peet, M., and Stokes, C. (2005). Omega-3 fatty acids in the treatment of psychiatric disorders. Drugs 65, 1051-1059. doi: 10.2165/00003495-200565080-00002

Perquier, F., Lasfargues, A., Mesrine, S., Clavel-Chapelon, F., and Fagherazzi, G. (2014) Body-size throughout life and risk of depression in postmenopausal women: findings from the E3N cohort. Obesity 22, 1926-1934. doi: $10.1002 /$ oby.20799

Pelletier, G., Li, S., Luu-The, V., and Labrie, F. (2007). Oestrogenic regulation of pro-opiomelanocortin neuropeptide $\mathrm{Y}$ and corticotrophin-releasing 
hormone mRNAs in mouse hypothalamus. J. Neuroendocrinol. 19, 426-431. doi: 10.1111/j.1365-2826.2007.01548.x

Pellow, S., Chopin, P., File, S. E., and Briley, M. (1985). Validation of open: closed arm entries in an elevated plus-maze as a measure of anxiety in the rat. $J$. Neurosci. Methods 14, 149-167. doi: 10.1016/0165-0270(85)90031-7

Porsolt, R. D., Le Pichon, M., and Jalfre, M. (1977). Depression: a new animal model sensitive to antidepressant treatments. Nature 266, 730-732. doi: 10.1038/266730a 0

Reeves, P. G. (1997). Components of the AIN-93 diets as improvements in the AIN-76A diet. J. Nutr. 127, 838-841. doi: 10.1093/jn/127.5.838S

Ren-Patterson, R. F., Cochran, L. W., Holmes, A., Lesch, K. P., Lu, B., and Murphy, D. L. (2006). Gender-dependent modulation of brain monoamines and anxiety-like behaviors in mice with genetic serotonin transporter and BDNF deficiencies. Cell. Mol. Neurobiol. 26, 1-25. doi: 10.1007/s10571-006-9048-6

Rivera, H. M., Santollo, J., Nikonova, L. V., and Eckel, L. A. (2012). Estradiol increases the anorexia associated with increased 5-HT2C receptor activation in ovariectomized rats. Physiol. Behav. 105, 188-194. doi: 10.1016/j.physbeh.2011.08.018

Robinson, L. E., and Mazurak, V. C. (2013). N-3 polyunsaturated fatty acids: relationship to inflammation in healthy adults and adults exhibiting features of metabolic syndrome. Lipids. 48, 319-332. doi: 10.1007/s11745-013-3774-6

Ronan, P. J., and Summers, C. H. (2011). Molecular signaling and translational significance of the corticotropin releasing factor system. Prog. Mol. Biol. Transl. Sci. 98, 235-292. doi: 10.1016/B978-0-12-385506-0.00006-5

Ross, B. M., Seguin, J., and Sieswerda, L. E. (2007). Omega-3 fatty acids as treatments for mentalillness: which disorder and which fatty acid? Lipids Health Dis. 6:21. doi: 10.1186/1476-511X-6-21

Ross, L. A., and Polotsky, A. J. (2012). Metabolic correlates of menopause: an update. Curr. Opin. Obstet. Gynecol. 24, 402-407. doi: 10.1097/GCO.0b013e32835a91bc

Ruzickova, J., Rossmeisl, M., Prazak, T., Flachs, P., Sponarova, J., Veck, M., et al. (2004). Omega-3 PUFA of marine origin limit diet-induced obesity in mice by reducing cellularity of adipose tissue. Lipids 39, 1177-1185. doi: $10.1007 / \mathrm{s} 11745-004-1345-9$

Santollo, J., Yao, D., Neal-Perry, G., and Etgen, A. M. (2012). Middle-aged female rats retain sensitivity to the anorexigenic effect of exogenous estradiol. Behav. Brain Res. 232, 159-164. doi: 10.1016/j.bbr.2012.04.010

Siddiqi, S. A., Kumar, N. S., St Hilaire, R. J., Nutting, D. F., and Mansbach, C. M. II. (2000). Nutrient Absorption. Curr. Opin. Gastroenterol. 16, 147-153. doi: 10.1097/00001574-200003000-00009

Silva, L. E., Castro, M., Amaral, F. C., Antunes-Rodrigues, J., Elias, L. L. (2010). Estradiol-induced hypophagia is associated with the differential mRNA expression of hypothalamic neuropeptides. Braz. J. Med. Biol. Res. 43, 759-766. doi: 10.1590/S0100-879X2010007500059

Singh, M. (2014). Mood, food, and obesity. Front. Psychol. 5:925. doi: $10.3389 /$ fpsyg.2014.00925

Tang-Christensen, M., Vrang, N., Ortmann, S., Bidlingmaier, M., Horvath, T. L., and Tschöp, M. (2004). Central administration of ghrelin and agouti-related protein (83-132) increases food intake and decreases spontaneous locomotor activity in rats. Endocrinology 145, 4645-4652. doi: 10.1210/en.2004-0529
Vancassel, S., Leman, S., Hanonick, L., Denis, S., Roger, J., Nollet, M., et al (2008). N-3 Polyunsaturated fatty acid supplementation reverses stress-induced modifications on brain monoamine levels in mice. J. Lipid Res. 49, 340-348. doi: 10.1194/jlr.M700328-JLR200

Vega-Rivera, N. M., López-Rubalcava, C., and Estrada-Camarena, E. (2013). The antidepressant-like effect of ethynyl estradiol is mediated by both serotonergic and noradrenergic systems in the forced swimming test. Neuroscience 250, 102-111. doi: 10.1016/j.neuroscience.2013.06.058

Venna, V. R., Deplanque, D., Allet, C., Belarbi, K., Hamdane, M., and Bordet, R. (2009). PUFA induce antidepressant-like effects in parallel to structural and molecular changes in the hippocampus. Psychoneuroendocrinology 34, 199-211. doi: 10.1016/j.psyneuen.2008.08.025

Watanabe, R. L., Andrade, I. S., and Telles, M. M., et al (2010). Longterm consumption of fish oil-enriched diet impairs serotonin hypophagia in rats. Cell. Mol. Neurobiol. 30 1025-1033. doi: 10.1007/s10571-0109533-9

Watanabe, R. L., Andrade, I. S., Zemdegs, J. C., Albuquerque, K. T., Nascimento, C. M., Oyama, L. M., et al (2009). Prolonged consumption of soy or fish-oil-enriched diets differentially affects the pattern of hypothalamic neuronal activation induced by refeeding in rats. Nutr. Neurosci. 12, 242-248. doi: 10.1179/147683009X423472

Witte, M. M., Resuehr, D., and Chandler, A. R. (2010). Female mice and rats exhibit species-specific metabolic and behavioral responses to ovariectomy. Gen. Comp. Endocrinol. 166, 520-528. doi: 10.1016/j.ygcen.2010. 01.006

Xiong, Q., Hu, X., Xu, Y., and Zhang, X. (2017). Association of visceral fat area with the presence of depressive symptoms in Chinese postmenopausal women with normal glucose tolerance. Menopause 24, 1289-1294. doi: 10.1097/GME.000000000 0000917

Yeo, G. S., and Heisler, L. K. (2012). Unraveling the brain regulation of appetite: lessons from genetics. Nat. Neurosci. 15, 1343-1349 doi: 10.1038/nn. 3211

Zhu, L., Xu, P., Cao, X., and Yang, Y. (2015). The ER $\alpha$-PI3K cascade in proopiomelanocortin progenitor neurons regulates feeding and glucose balance in female mice. Endocrinology. 156, 4474-4491. doi: $10.1210 /$ en.2015-1660

Conflict of Interest Statement: The authors declare that the research was conducted in the absence of any commercial or financial relationships that could be construed as a potential conflict of interest.

Copyright (c) 2018 Dornellas, Boldarine, Pedroso, Carvalho, de Andrade, VulcaniFreitas, dos Santos, do Nascimento, Oyama and Ribeiro. This is an open-access article distributed under the terms of the Creative Commons Attribution License (CC $B Y)$. The use, distribution or reproduction in other forums is permitted, provided the original author(s) and the copyright owner(s) are credited and that the original publication in this journal is cited, in accordance with accepted academic practice. No use, distribution or reproduction is permitted which does not comply with these terms. 